\title{
Using Business Software In The Classroom: A Case-Based Approach
}

Robert C. Zelin II, (Email: robert.zelin@mnsu.edu), Minnesota State University, Mankato Jane E. Baird, (Email: jane.baird@mnsu.edu), Minnesota State University, Mankato

\begin{abstract}
This paper reports on the use of a technology-based case in three undergraduate accounting courses. The project was a hands-on collaborative learning application that involved a simulated manufacturing exercise and utilized Excel, Access and IDEA software. The students reported that they liked the learning by doing approach and appreciated the opportunity to apply the concepts learned in a practical, real-world type of situation. Test scores indicated that the case activities helped the students learn the desired concepts.
\end{abstract}

\section{INTRODUCTION}

\begin{abstract}
Whe Accounting Education Change Commission (AECC) challenged accounting educators to engage students as active participants in the learning process and to encourage students to identify unstructured problems and solve those problems (AECC, 1990). In addition, educators have been asked to incorporate more technology into the accounting curriculum and broaden the scope of the curriculum to meet the needs of the profession (e.g. Albrecht and Sack, 2000; Elliott, 1997; Williams, 1993). The need for these skills is perhaps even more evident today in light of recent revelations of highly-complex corporate accounting scandals. Students need to be prepared to work in a quick-changing, complex environment. A "learning by doing" approach is often proposed as a means of meeting the challenge, particularly in regard to the use of case studies (e.g. Baird and Higgins, 1998; Campbell, 1985; Campbell \& Lewis, 1991; Libby, 1991; Knechel, 1992; Stewart \& Dougherty, 1993; McMillan, 1994). This paper reports on a project involving the development and implementation of case materials used in three courses in the accounting curriculum at one Midwestern university. The cases involved simulation and the use of technology in cost accounting, accounting information systems, and internal auditing.
\end{abstract}

\section{THE USE OF CASES}

The use of cases offers a means to present unstructured, "real-world" types of problems to students in an interesting way, and encourage students to develop their problem-solving skills in applying concepts learned in the classroom to the case problems. The use of cases can increase student interest and motivation, aid in the development of communication skills and problem-solving skills, and increase students' understanding of the "real world" (Libby, 1991; Stewart and Dougherty, 1993). A case approach has been shown to improve learning in a variety of accounting courses (Anderson et al., 1990; Anderson et al., 1989; Innes and Mitchell, 1981; Mohrweis, 1993; Stewart \& Dougherty, 1993; Pointer \& Ljungdahl, 1973). The use of professional software in conjunction with case activities can accomplish these objectives while also improving the students' computer skills.

\section{THE CASE}

This project involved the development and implementation of a hands-on collaborative learning application integrated across three undergraduate courses in the accounting curriculum at one university. The courses in which the case was used were Cost Accounting (first phase), Accounting Information Systems (second phase), and Internal Auditing (third phase). However, the entire exercise could be integrated into one or two Accounting Information Systems courses. The first two courses were required courses for accounting majors, while the third course was an elective. Although the Cost Accounting course is not a prerequisite for the Accounting Information Systems course, 
most students do take the Cost Accounting course first. The Accounting Information Systems course was required for the Internal Auditing course. Because not all students would be completing the courses in sequence, the case was designed so that each part could be used as a stand alone case in the appropriate course, even though the three parts of the case were interrelated.

The students completed different activities in each of the three phases based on the same hypothetical company, Galaxy Motors. All case materials were developed by the faculty members teaching the courses. The students received brief background information on the company in order to familiarize them with the company's business.

The course learning objectives for the first phase of the case and the specific case objectives related to those course objectives were:

- To understand and apply conventional costing methods, such as job order and process costing, including: the ability to utilize complex inventory and production information in order to calculate a value for the Beginning Inventory using the weighted average and FIFO method, the ability to utilize complex inventory and production information in order to calculate a value for the Ending Inventory using the weighted average and FIFO method and the ability to utilize complex inventory and production information in order to calculate a value for the goods transferred to the next department using the weighted average and FIFO

- To demonstrate the ability to collect data from a simulated manufacturing process and transfer the data to an Excel worksheet

- $\quad$ To demonstrate the ability to work effectively in teams to complete a complex task

In phase one, the activity included a simulation of a manufacturing process. Using character recognition scanning equipment and LEGO building sets, student teams simulated the manufacturing process and designed inventory accounting reports from the data collected during the manufacturing process. Students worked cooperatively in teams to assemble the products and create process costing reports to record the work being done, as it would be recorded in an accounting system. The LEGO parts had all been assigned part numbers and arranged into inventory bins as part of the development of the case materials. The part numbers were typed on bin labels so that they could be scanned by the students. The scanned information was uploaded into a Microsoft Excel spreadsheet.

In the second phase, the course learning objectives related to the tasks were:

- $\quad$ To demonstrate the ability to work effectively in teams to complete a complex task

- To demonstrate a familiarity with software programs in the areas of database management and accountingrelated services, including the ability to import Excel data into Access, create database tables, create input forms, create reports, create a switchboard, create a customized toolbar and implement customized macros

- $\quad$ To demonstrate creativity in the design of the database management system and its subcomponents

Phase Two students worked collaboratively in small groups to import the Excel inventory data created in the first phase into a Microsoft Access database. They then designed various reports along with corresponding input forms. The reports developed were payroll register, payroll check system, inventory drawer labels, direct materials inventory update, direct materials used in production, direct labor and overhead used in production and process costing. The teams were required to incorporate a switchboard, a customized toolbar and customized macros into their inventory and payroll management system.

In the third phase, the students learned how to import the Access and Excel information from the other two phases into IDEA software and use the software to complete audit tasks. IDEA software is a tool used by auditors as well as other accountants and investigators to perform data extraction and file interrogation as well as sampling and other applications. The software product is similar to the popular ACL product and all tasks completed in this phase of the case can also be performed using ACL. The learning objectives for phase three were:

- To demonstrate a knowledge of IDEA software, its basic functions, and how to use those functions for the 
completion of basic audit tasks

- $\quad$ To demonstrate the ability to use audit software (IDEA) to complete audit tasks, including these specific skills: importing files from Excel and Access into IDEA, change data formatting, add a virtual variable to the data file, join files, and use the Extract, Reports, Duplicates, and Gap Detection functions effectively

- $\quad$ To demonstrate the ability to design audit tasks by designing a test of an inventory application

- To demonstrate the ability to communicate audit results effectively by writing an effective report to management summarizing the results of the audit procedures performed in the case

The data from the first two courses were expanded and adjusted in the following ways to meet the needs of the tasks. A worksheet was added for the auditor's completed inventory count, using the product numbers and descriptions from the earlier case but adding "quantity counted" data and "tag number" data. Some items were purposely given counts differing from the reported quantities on hand to determine if the students could find the discrepancies. An additional worksheet was added to include management's desired minimum quantities along with the already existing product descriptions, part number, and drawer number. This information was used by the students to determine how many instances quantities on hand were less than the desired minimums. Finally, an Access table was created with payroll information for the month of April, including hours worked and gross pay. Students used this data to locate employees being paid more than their approved wage rate.

The students used the IDEA software to analyze the company's information and complete an audit of certain inventory and payroll processes. Tasks included importing data from Excel and Access, joining files, assessing reported problems with the company's perpetual inventory system, searching for missing inventory and doublecounted inventory, examining problems with product shortages, and searching for unauthorized pay rates used. Students wrote an executive summary that reported their findings to the management of Galaxy Motors.

\section{ASSESSMENT OF THE PROJECT}

In order to determine the effectiveness of the case, student examination questions were analyzed, the completed cases were evaluated, and student surveys were administered. There were 38 students in the first course, 26 in the second course, and 13 students in the third course. All students completed the cases and the examination questions, while the surveys were done on a voluntary basis.

\section{TESTING PROCEDURES}

Certain of the learning outcomes for the case were evaluated through testing in phase one and phase three. In the first phase, a pretest/post-test methodology was employed. In the third phase, answers to multiple choice examination questions about the IDEA software were analyzed.

Students in the first phase completed a pretest instrument prior to studying the concept of process costing and prior to working on the Lego project. The pretest had no effect on their course grade. The pretest contained sixteen multiple choice questions covering various components of process costing. Some questions were theoretical or definitional in nature and others involved calculations using the weighted average and FIFO approaches. These questions covered the first learning objective of this phase of the case, "To understand and apply conventional costing methods such as job order and process costing."

Once the pretest was completed, it remained in the custody of the instructor. After the material on process costing was covered in class and the "learning by doing" activity was completed, students took their second examination. The post-test questions were part of an examination covering three chapters in the textbook, one of which was process costing. In order to keep the examination to a reasonable length, only eight of the original sixteen pretest questions were used. The eight questions used were a representative sample of the pretest questions.

Analysis of the pretest and examination (post-test) data revealed overall improvement in almost every student's score. When the percentage on the pretest was subtracted from the percentage on the examination, the following differences resulted: 
Table 1

\begin{tabular}{|c|c|c|c|c|c|c|}
\hline \multicolumn{7}{|c|}{ Percentage Score Improvement: Pretest to Post-test } \\
\hline Exam \% - Pretest \% & -10 to $0 \%$ & 0 to $10 \%$ & 10 to $20 \%$ & 20 to $30 \%$ & 30 to $40 \%$ & $>40 \%$ \\
\hline Number of Students & 1 & 3 & 8 & 14 & 8 & 4 \\
\hline
\end{tabular}

When the eight common questions on the pretest were subtracted from the eight common questions on the examination, the following differences resulted:

Table 2

\begin{tabular}{|c|c|c|c|c|c|c|}
\hline \multicolumn{7}{|c|}{ Score Improvement: Number of Questions } \\
\hline Exam - Pretest & -2 & -1 & 0 & 1 & 2 & 3 \\
\hline Number of Students & 2 & 1 & 5 & 14 & 10 & 6 \\
\hline
\end{tabular}

As can be seen from the results, the vast majority of students' scores did improve between the pretest and the posttest examination.

The success of the case in the third phase was assessed through eight multiple choice questions on the final examination for the class. The questions related to the data analysis software used to perform various tasks. These questions directly measured the first learning objective of phase three: "To demonstrate a knowledge of IDEA software, its basic functions, and how to use those functions for the completion of basic audit tasks".

As summarized in Table 3, the students scored very well on these questions, with 4 out of 13 students answering all eight questions correctly, 8 of the thirteen missing only one of the eight questions (87.5 percent correct), and one student missing 2 out of the eight questions ( 75 percent correct). No student scored less than a 75 percent on these questions, whereas the overall examination scores went as low as 57 percent. The case was the only exposure the students had to the software, so all learning related to the software was directly linked to the case.

Table 3

\begin{tabular}{|c|c|c|}
\hline \multicolumn{3}{|c|}{ Test Results for Phase Three: IDEA Software Questions } \\
\hline & Number of Students & Percent of Total Class \\
\hline Perfect Score (100\%) & 4 & $31 \%$ \\
\hline Missing only 1 of 8 Questions (87.5\%) & 8 & $61 \%$ \\
\hline Missing 2 of 8 Questions (75\%) & 1 & $8 \%$ \\
\hline
\end{tabular}

\section{CASE EVALUATION}

After the manufacturing simulation was completed in Phase One, the students then worked on the process costing reports. A review of the process costing reports revealed that the students had met the learning outcomes of being able to collect data from a simulated manufacturing process and transfer the data to an Excel worksheet, to work effectively in teams to complete a complex task and to understand and apply the process costing method. The results of the manufacturing simulation and the process costing report were evaluated as a homework assignment. Each phase comprised about two percent of the student's grade in the course.

In the second phase, student groups (five to six members) were asked to create a database management system. This incorporated learning outcomes that included importing Excel data into Access and creating database tables, input forms, reports, a switchboard, customized toolbars and macros. Each group presented its database management system to the class, the instructor and an outside observer who was a practicing CPA. The outside observer prepared written comments on each group and rank ordered the groups. Each student provided comments and assigned a number grade to the group. Finally, the instructor took under advisement the feedback from the 
outside observer and the individual students when he reviewed his comments and decided on a grade for each group. Each group exceeded the minimum requirements for the learning outcomes mentioned above. Additionally, the learning outcomes of creativity and teamwork were also taken into consideration in determining a final grade on the project. The creativity and innovation demonstrated by some groups resulted in a higher grade being assigned to the group. Finally, a teamwork grade adjustment was calculated. Each team member evaluated the other members of her or his team in terms of the member's contribution to the final product. The result of this grade adjustment process was that a few students in the class received a lower score than their other team members and a few students in the class received a higher score than their other team members. The grades on the case ranged from a very low B to a high A. The case was worth approximately 25 percent of the student's grade.

In Phase Three, the evaluations of the students' case solutions were used to assess the learning outcomes 'to demonstrate the ability to use audit software (IDEA) to complete audit tasks", "to demonstrate the ability to design an audit task to test an inventory application", and "to demonstrate the ability to communicate audit results effectively." Since these objectives related to actually performing tasks, they were better suited for evaluation through the case tasks than through testing on examinations. The cases were evaluated based on whether or not the student was able to complete all of the audit tasks successfully with the correct results, format their reports professionally, and communicate the results effectively in a summary report to management. All cases were graded by the instructor, so there was some subjectivity involved in regard to the written communications evaluation.

The case evaluation grades are summarized in Table 4 . Of the 13 students in the course, seven earned perfect scores on the project, indicating they obtained all the correct audit results, formatted their reports professionally, and wrote clear, concise, accurate, and professional reports for management. Two additional students also earned an A on the project, but had minor formatting or grammatical errors in their reports. Of the remaining four students, three earned a grade of B. All three of those students had successfully completed all of the audit tasks with minor exceptions, primarily falling short in one or both of the following areas: not designing an adequate or efficient audit task for the last step of the audit (the only one in which they had to design their own procedures) and not preparing an effective report. Only one student out of the 13 earned lower than a B, and that student did not complete all of the audit tasks assigned in the project.

Table 4

\begin{tabular}{|c|c|c|}
\hline \multicolumn{3}{|c|}{ Case Evaluation Results for Phase Three } \\
\hline & Number of Students & Percent of Total Class \\
\hline A Grade & 9 & $69 \%$ \\
\hline B Grade & 3 & $23 \%$ \\
\hline C or Below & 1 & $8 \%$ \\
\hline
\end{tabular}

These results indicate that all the students were able to use the software effectively on directed tasks, and most were able to also demonstrate the ability to design their own procedures to address a given audit objective. The students were only asked to design one of the audit tests on their own. This was a more difficult task than merely following directed audit steps in that it required application of learned tasks to a totally new situation. While the A and B students in the course had no trouble with this, the less gifted students struggled with it somewhat. While most students demonstrated the ability to communicate their results effectively, that learning outcome provided the least successful results. The students had studied how to prepare effective reports earlier in the semester, but the case itself did not include teaching of these concepts.

\section{STUDENT SURVEYS}

Students in all three phases were surveyed to determine if the students felt the case-based project had a positive effect on their learning process. All surveys were anonymous.

In the first phase, eighteen students responded to the survey. Nine reported their major as accounting, followed by four finance majors, four management majors and one other major. Twelve of the responding students were classified as Juniors and the remaining students were classified as seniors. Twelve students were males, six were 
females.

The results to selected survey questions are summarized in Table 5. As seen in Table 5, a majority of the students thought the project made learning "more fun" or "fun", and that "much more" or "more learning took place" as a result of the project. Approximately half of the students felt that the project increased their retention level with respect to the subject matter. When asked an open-ended question about the strengths of the project, many students commented on the hands-on aspect of the project, the real world aspect of the project and the enjoyment of doing something outside of the textbook.

When asked about suggested improvements for the project, students commented that the project should be done all at once instead of being broken into segments, the groups should be smaller and that more class time should be devoted to the project. The group size ranged from four to six students. This group range worked well for the manufacturing simulation portion of the exercise because the product had 99 parts and would have required too much time with fewer students. However, the group range did not work well for the creation of the process costing report. For each group one or two individuals took the lead in writing the report. Ideally, the report phase should have been structured so that each individual or pairs of individuals should have created a report. Thus, each group would be producing between three and six reports. In regard to the time allotted for the case, one 75 minute class period was allocated to the manufacturing simulation and a portion of one class period (approximately 20 minutes) was devoted to explaining the reporting phase. The students were required to do the calculations outside of class. The survey results indicated that the students wanted to complete the reporting phase in class because the group size was large and scheduling a group time outside of class was often difficult.

The final survey question addressed whether the project should be used in future classes. Fifteen (83\%) students responded "yes".

In the second phase, twenty five students responded to the same survey used in phase one. Twenty students reported being accounting majors. The remaining students reported either finance or management as their major. Thirteen students were classified as juniors and twelve were classified as seniors. Eighteen of the students were female.

As seen in Table 5, students were evenly divided between feeling that the project made learning about databases "more fun" or "fun" and that it made learning either "not fun" or "a real burden." When asked about the effect of the project on their learning about databases, seventeen (68\%) students reported that "much more" or "more learning took place." In terms of retention levels, sixteen (64\%) students reported a "much greater" or "greater" retention level as a result of using the case.

When asked an open-ended question about the strengths of the project, students commented that the project helped them to apply what they had learned in class to a real life situation, the project allowed them to be creative, the project helped them to get to know their classmates, the project allowed them to learn from their mistakes and made them realize the effort that database professionals must put forth. When asked an open-ended question about how the project could be improved, the students wanted more structure and detailed instructions. Additionally, they suggested that more time was needed for the project and that groups should be smaller. Some students did not like the process costing report aspect of the project because the material was covered at an earlier time in their academic career. When asked if the project should be used in future classes, sixteen (64\%) students stated "yes." 
Table 5

\begin{tabular}{|c|c|c|}
\hline \multicolumn{3}{|c|}{ Survey Results for Phases One and Two Number of Students Responding } \\
\hline Survey Question: & Phase $1 \mathrm{n}=18$ & Phase $2 \mathrm{n}=\mathbf{2 5}$ \\
\hline $\begin{array}{l}\text { The Lego project made learning about process costing/databases: } \\
\text { More fun } \\
\text { Fun } \\
\text { Had no effect } \\
\text { Not fun } \\
\text { A real burden }\end{array}$ & $\begin{array}{l}8 \\
5 \\
2 \\
2 \\
1 \\
\end{array}$ & $\begin{array}{l}4 \\
7 \\
3 \\
3 \\
8 \\
\end{array}$ \\
\hline $\begin{array}{l}\text { The Lego project's effect on my learning about process costing/databases was: } \\
\text { Much more learning took place } \\
\text { More learning took place } \\
\text { No change in learning } \\
\text { Less learning took place } \\
\text { Much less learning took place }\end{array}$ & $\begin{array}{c}2 \\
10 \\
5 \\
0 \\
1\end{array}$ & $\begin{array}{c}3 \\
14 \\
6 \\
1 \\
1\end{array}$ \\
\hline $\begin{array}{l}\text { Due to the Lego project, my retention level with regard to things that I learned } \\
\text { about process costing/databases is } \\
\text { Much greater } \\
\text { Greater } \\
\text { No effect } \\
\text { Decreased } \\
\text { Greatly decreased }\end{array}$ & $\begin{array}{l}0 \\
9 \\
7 \\
1 \\
0\end{array}$ & $\begin{array}{c}4 \\
12 \\
7 \\
0 \\
1\end{array}$ \\
\hline
\end{tabular}

In the third phase, the students were also surveyed in order to assess their opinions about the project. This survey was conducted by a different instructor than in phases one and two, and the survey questions were different in wording from those in the first and second classes but were of a similar nature and content. Eleven out of thirteen students in the class completed the survey. There were nine statements that used a Likert-type scale ranging from 1 (strongly disagree) to 7 (strongly agree). Table 6 lists the statements used and summarizes the results. These scores indicate a high level of agreement by the students that the case helped them increase their skills and understanding of the topic, and that the case should be continued in future classes. The students also seemed to enjoy completing the case materials and felt that the case was a good one. The students disagreed with the statement that they could have learned the same things from a lecture that they learned from the case. This indicates that they valued the learning by doing concept.

The students were also asked some open-ended questions on the survey. When asked what they liked best about the case, the most common response was that they liked the hands-on approach. They also liked the practical nature of the task that gave them experience with skills they will use in their jobs. When asked what they liked least about the case, one student commented that he or she needed more time to complete the project. Another student indicated that he/she did not like the software and would like to use a different package. One student noted that the case was somewhat complicated. When asked what could be done to improve the case, the students commented that they would have liked to complete more similar cases and do more applications with the software. 
Table 6

\begin{tabular}{|l|c|}
\hline \multicolumn{1}{|c|}{ Internal Audit Survey Results } & $\begin{array}{l}\text { Mean Student Rating } \\
\text { (scale=1-7,7=strongly agree) }\end{array}$ \\
\hline Statement & 6.18 \\
\hline This case helped me to increase my skills in using the data analysis software & 5.82 \\
\hline I found this case interesting & 6.09 \\
\hline $\begin{array}{l}\text { This case helped me to understand how computer assisted audit techniques can be used within } \\
\text { an organization }\end{array}$ & 6.36 \\
\hline The length of time to complete the case was reasonable & 6.09 \\
\hline $\begin{array}{l}\text { Completing this case helped me to better understand the types of activities that internal } \\
\text { auditors do in their jobs }\end{array}$ & 5.82 \\
\hline I enjoyed completing the case activities & 6.27 \\
\hline I would recommend using this case in future classes & 3.09 \\
\hline I could have learned the same things from a lecture that I learned from doing this case & 6.00 \\
\hline Overall rating of the case & \\
\hline
\end{tabular}

\section{SUMMARY AND CONCLUSIONS}

This project illustrates that a case-based approach can be used to simultaneously teach students accounting related concepts and provide them with skills in using software packages commonly utilized by accounting professionals. In all three phases, the students reported that the case helped them to learn the concepts covered in the course and that they liked the "learning by doing" approach. The students also appreciated the opportunity to apply the concepts learned in a practical, real-world type of situation. The students overwhelmingly indicated that the case should be used in future classes. In addition, test scores provided an objective measure that the case activities were successful in helping the students to learn desired concepts. Only the Cost Accounting phase of the case proved to be somewhat troublesome due to the time involved in completing the simulation task. The Lego sets chosen for the project had 99 pieces, making the assembly time consuming.

This particular case involved the use of Excel, Microsoft Access, and IDEA data analysis software. These products are frequently used within the business community. The use of case activities that incorporate frequently used software can provide students with the skills they need to enter an increasingly demanding workplace.

It should be noted that these results are based on fairly small sample sizes and that the survey measures provide indirect evidence regarding the case benefits rather than direct evidence. In addition, there is the possibility of subjectivity in the grading of the cases themselves. The test results do provide a direct measurement of learning, and those results, combined with the surveys and case evaluation, do suggest that the case was successful in meeting its learning outcomes.

\section{SUGGESTIONS FOR FUTURE RESEARCH}

Future research could further explore the impact of a hands-on case approach to learning by comparing achievement of a "no case" control group against a treatment group using the cases. It would also be interesting to perform a longitudinal study tracking students through all three courses to measure the effects of the case on skills such as effective teamwork and communication. In addition, the effectiveness of varying types of cases could be studied. For example, does hands-on simulation improve the effectiveness of a case? Do shorter cases affect learning differently than longer, more comprehensive cases? Further research in this area can benefit both professors and students in improving the learning process. 


\title{
REFERENCES
}

1. Accounting Education Change Commission (AECC), Objectives of Education for Accountants: Position Statement No. One, Issues in Accounting Education, Vol. 5, pp. 307-312, 1990.

2. Albrecht, W. and R. Sack, Accounting Education: Charting the Course through a Perilous Future. Accounting Education Series, Vol.16, American Accounting Association, Sarasota, FL, 2000.

3. Anderson, U., G. Marchant and J. Robinson, Instructional Strategies and the Development of Tax Expertise, Journal of the American Taxation Association, Vol. 10, pp. 7-23, 1989.

4. Anderson, U., G. Marchant, J. Robinson, and M. Schadewald, Selection of Instructional Strategies in the Presence of Related Prior Knowledge, Issues in Accounting Education, Vol. 5, pp. 41-58, 1990.

5. Campbell, J.E. and W.F. Lewis, Using Cases In Accounting Classes, Issues in Accounting Education, Vol. 6, pp. 276-283, 1991.

6. Campbell, T.L., Teaching Internal Auditing With Cases, The Internal Auditor, Vol. 42, pp. 40-42, 1985.

7. Elliott, R., Assurance Service Opportunities: Implications for Academia, Accounting Horizons, Vol. 11, pp. 61-74, 1997.

8. Innes, J. and F. Mitchell, Auditing Case Studies: Just How Useful Are They?, Accountancy, Vol. 92, pp. $127-128,1981$.

9. Knechel, R.W., Using the Case Method in Accounting Instruction, Issues in Accounting Education, Vol. 7, pp. 205-217, 1992.

10. Libby, P.A., Barriers to Using Cases in Accounting Education, Issues in Accounting Education, Vol. 6, pp. 193-213, 1991.

11. McMillan, J.J., Identifying and Closing Gaps in the Judgment and Behavior of Auditing Students and Staff Auditors, Issues in Accounting Education, Vol. 9, pp. 282-300, 1994.

12. Mohrweis, L.C., Teaching Audit Planning and Risk Assessment: An Empirical Test of the Dermaceutics Instructional Resources, Issues in Accounting Education, Vol. 8, pp. 391-403, 1993.

13. Pointer, L.G. and P.W. Ljungdahl, The Merit of Using the Case Method in Teaching the Specialized Accounting Course, The Accounting Review, Vol. 48, pp. 614-618, 1973.

14. Stewart, J.P. and T.W. Dougherty, Using Case Studies in Teaching Accounting: A Quasi-Experimental Study, Accounting Education, Vol. 2, pp. 1-10, 1993.

15. Williams, D., Reforming Accounting Education, Journal of Accountancy, Vol. 176, pp. 76-81, 1993.

\section{APPENDIX: CASE MATERIALS}

The following are the written portions of the case materials and instructions developed by the faculty members and used in the three courses. The cases also included simulated inventory warehouses for the product parts, which were stocked with the actual Lego product parts, and data files for the company's inventory and payroll records.

\section{Management Accounting Course}

\author{
Galaxy Motors Case \\ Process Costing Simulation
}

\section{Background:}

Galaxy Motors, Inc. manufactures an all-terrain vehicle, the T3-Trike, that is used by the space program in the exploration of other planets. You are an employee in the first department, the assembly department, in the manufacturing process. The company has a second department, the packaging department. In this exercise, you will simulate the manufacturing process at Galaxy Motors in order to determine the company's product costs. You will have four to six employees on the assembly line. Two of these employees make $\$ 15$ per hour and perform the most skilled portions of the assembly. All remaining employees make $\$ 14$ per hour. The company is starting production with one unit in process. The partially completed unit is finished through step 4 on page 3 in your booklet and step 5 on page 10 in your booklet. 
You will be provided with the following materials:

1. An Excel spreadsheet, located on the course Web site, containing the part number, drawer number, part description, unit price and quantity in stock for each unit produced,

2. An inventory storage unit containing your company's inventory,

3. A hand-held scanner,

4. A stop watch, and

5. An assembly instruction booklet.

\section{Instructions:}

You will first need to divide the assembly tasks among your group members. To do this you must review the assembly instruction booklet and determine which tasks are the most difficult. You will not assemble the little man. These tasks should be assigned to the two workers earning the highest wage. Then, assign all other tasks to the rest of the assembly team. Place the drawers containing the appropriate parts in front of each assembly team worker. Next, assemble the units of beginning inventory to the point indicated above for each unit. You will need to track which parts are used, how many of each part are used, and how long each person spends on the assembly in order to track material and labor costs. A stop watch is provided for measuring the time. For recording the time, use the actual time multiplied by ten. Note this information by hand for later incorporation into your spreadsheet. You will be provided with a worksheet to help you.

Next, assume that you are entering a new production run. First, you will complete the assembly of the beginning Work-in-Process inventory. Next, you will produce three complete units. Finally, you will partially produce one unit that will represent ending inventory. The unit will be complete through step 7 on page 3 and through step 6 on page 13. With the hand-held scanner you will record the part number and quantity used from the label on the side of each tray. You will need to manually record the total time per person spent on finishing the beginning inventory, producing the five units and beginning the ending inventory. The table found below may help you with your recordkeeping. Once again, use the stop watch for this purpose and multiply the actual time by ten.

Once this information is recorded, check with the supervisors to make sure that you have recorded the appropriate information. Return the scanner to the supervisors and dis-assemble the units and place the parts back in their appropriate drawers.

Within the next week, use the Excel spreadsheet to calculate the value of the beginning inventory. Calculate the amount in direct materials, direct labor and overhead. Direct labor time for beginning inventory is 40 minutes at the rate of $\$ 14$ per hour. Overhead cost for this company is 1.5 times the direct labor cost. Present the material in the form of an Excel spreadsheet.

Next week you will be provided with an Excel spreadsheet of the items that you scanned during the simulation. From that spreadsheet and the original inventory information spreadsheet, you will calculate the equivalent units of production, the equivalent cost per unit, the dollar amount transferred to the next department and the dollar amount left in ending inventory. Prepare the report using Excel. Show detail calculations for direct materials, direct labor and overhead.

Labor Time Table

\begin{tabular}{|l|l|l|l|c|c|}
\hline Worker Name & Start Time & Stop Time & Difference* & Times Ten & Time Worked* \\
\hline & & & & 10 & \\
\hline & & & & 10 & \\
\hline & & & & 10 & \\
\hline & & & & 10 & \\
\hline & & & & 10 & \\
\hline
\end{tabular}

* convert seconds to 2 decimal places- i.e. 15 seconds $=.25,30$ seconds $=.5$ 


\title{
Galaxy Motors Case \\ Process Costing Problem
}

In a previous class period, you and your group did a process costing simulation where you aided in the manufacture of an all-terrain vehicle, the T3-Trike. This exercise is based on your experience with the simulation. The goal of this exercise is for you to value the beginning inventory, value the ending inventory and value the products sent to the next department, packaging, using the weighted average and FIFO method.

\section{Beginning Inventory:}

You must calculate the value of the beginning inventory in terms of direct materials, direct labor and overhead costs. Additionally, you must determine the percentage of completion for materials and conversion costs for the beginning inventory. In order to do this you may need to reconstruct the beginning inventory. Use the stop watch to determine your time. Refer to the original instructions for the wage rates. Please remember to multiply the actual time by ten. In order to determine the cost of beginning inventory, use the Excel worksheet provided. On the worksheet, you will find the cost for each item of direct material.

\section{Ending Inventory:}

Initially, you must determine the percentage of completion for materials and conversion costs for ending inventory. The value of direct materials, direct labor and overhead costs will be determined when you apply the weighted average or FIFO method to the problem.

\section{Products Sent To The Next Department:}

You will determine the value of direct materials, direct labor and overhead costs that are sent to the next department. Your valuation should be done under both the weighted average and FIFO method.

\section{Assignment:}

Prepare a cost of production report using the weighted average and FIFO method.

\section{Accounting Information Systems Course}

Lego Case Fact Sheet

The client requests that the following reports be developed:

\author{
Payroll Register \\ Payroll Check System \\ Inventory Drawer Labels \\ Direct Materials Inventory Update \\ Direct Materials Used in Production \\ Direct Labor and Overhead Used in Production \\ Process Costing
}

\section{Input facts:}

4 employees- 2@\$14/hr; 2@\$15/hr

FICA $=7 \%$; State Tax Rate $=5 \%$; Federal Tax Rate $=15 \%$

Beginning Raw Materials Inventory= 20 times inventory to make one unit

Each employee worked 3 hours during the period 
Overhead=Direct Labor Cost times 1.5

Beginning Work in Process Inventory $=.2$ units (same for materials and conversion cost)

Ending Work in Process Inventory $=.25$ units (same for materials and conversion cost)

\section{Process Costing Information:}

Units in Beg WIP Inv $\quad 0.20$

Units Started $\quad 6.00$

Units in End WIP Inv $\quad \underline{0.25}$

Units Completed and Transferred $\quad \frac{0.25}{5.95}$

Units Completed and Transferred $\quad 5.95$

+ Equivalent Units in End WIP Inv $\underline{0.25}$

Equivalent Units-Weighted Average Method $\quad \frac{0.25}{6.20}$

\begin{tabular}{|c|c|c|}
\hline & Materials & Conversion Costs \\
\hline Costs in Beg WIP Inv & Costed-out beginning inventory & $(\mathrm{X} / 6.05)^{*} .2$ \\
\hline Costs added during period & $\begin{array}{c}\text { Costed-out inventory used in the } \\
\text { manufacturing process }\end{array}$ & Labor and Overhead Costs for the period=X \\
\hline Total Costs & 6.2 & 6.2 \\
\hline Divided by Equiv. Units & & \\
\hline Cost per Equiv. Unit & & \\
\hline
\end{tabular}

\section{Determine:}

Value of the six units transferred to the packaging department

Value of the Ending Work in Process Inventory

\section{Grade Evaluation:}

You will be evaluated on the quality of your tables, queries (if any), input forms, reports, switchboard(s), toolbars, relationships and macros. Your system must not only look good, it should be functional. The sophistication level of your product will also be taken into consideration. A local accounting professional will provide me with comments about your product. I alone will assign the final grade.

You will be asked to evaluate the contribution of each of your group members in the following format:

You have 100 effort points to assign to each of the group members including yourself. If there are five members in the group and each worked an equal amount, everyone will receive 20. If the effort was not equal, then some members may receive more and others less. Depending on the evaluations, a group member's grade may increase or decrease from the group average by up to 3 percentage points.

What You Need to Submit:

A cover sheet with your consulting firm's name and the team member's names

A copy of each of your reports

The first page of all of your forms including any switchboards

A screen shot of any toolbars you created

A list of all of your macros along with the detailed steps within each macro

A screen shot or print out of your relationships

The disk that you did all this great work on 


\title{
Internal Audit Class
}

\author{
Galaxy Motors Case \\ Inventory And Payroll Audit Tests
}

\section{Background:}

Galaxy Motors, Inc. manufactures an all-terrain vehicle, the T3-Trike, that is used by the space program in the exploration of other planets. The company is a relatively small company, as there is limited demand for its product. Galaxy purchases all components of its vehicle from suppliers, but does all assembly in-house. The company maintains its payroll records in Microsoft Access and its inventory records in Microsoft Excel. You are the company's only internal auditor. You have been asked by management to address the following concerns by applying audit procedures to determine the extent of any problems:

- Management believes that its payroll process is vulnerable to error and manipulation because all data, including employee ID numbers and pay rates, are input manually by the payroll clerk each month to generate the paychecks. There is no systematic check to determine that proper pay rates have been used. They have asked you to test the payroll rates used for the month of April.

- Management is concerned that the perpetual inventory may not be accurate. At management's request, you have already completed a detailed count of all inventory on hand as of the end of last month. You will need to follow up on this procedure by comparing the results of your physical count with the company's perpetual records.

- Management has been notified by the production manager that there have been production slow-downs due to parts shortages. Management has a policy of minimum quantities that must be kept on hand to keep shortages from occurring. However, it appears that this policy is not being followed by the inventory manager. Management would like you to gather evidence on this issue and summarize the extent of the problem.

You will be provided with the following data files:

1. Four Excel Spreadsheet files containing inventory information:

a. Inventorycount.xls: includes part number, drawer number, inventory count tag number, description, quantity counted

b. Perpetualinventory.xls: includes part number, drawer number, description, and quantity on hand (per the books)

c. Minimumquantities.xls: includes part number, drawer number, description, and management's designated minimum stock levels for each part

d. Inventorymaster.xls: includes part number, drawer number, description, price per unit, and quantity of each part needed to produce on vehicle.

2. An Access database, called Payroll, containing two tables related to the company's payroll:

a. AprilPayroll table, which includes the month, year, employee number, hours worked, and gross pay for the month.

b. Employees table, which includes the employee number, social security number, name, address, and approved wage rate.

\section{Instructions:}

You will use the IDEA version 3.0 software to complete all of the required tasks in this case. The tasks are designed 
to have very detailed instructions for the earlier audit procedures and less structured directions for the later procedures to see if you can apply what you have learned regarding the audit software. At the completion of the case, you should turn in the following printed reports:

1. Pay rate comparison report showing any employees paid a rate other than the approved pay rate.

2. Per item inventory comparison that shows which items differed when the perpetual inventory was compared to the inventory count records.

3. Formal report showing the total inventory adjustment needed to reconcile the book records to the physical count.

4. A report showing any gaps in the sequence of tag numbers used in the physical inventory.

5. A report showing any duplicate tag numbers appearing in the inventory count records.

6. A report showing any unauthorized tag numbers used in the inventory count records.

7. A report showing all items for which the quantities on hand per the books are less than the required minimum quantities.

8. A brief summary of all testing results.

\section{PART 1}

\section{Audit Objectives:}

To determine if any employees are being paid at a rate that is different from their approved wage rate.

\section{Audit Procedures:}

1. Designate a: $\backslash$ Galaxy Motors as your working folder. Use the import assistant to import the Aprilpayroll table from the Access database file called Payroll. You may need to expand the column widths to see the entire column headings.

2. Verify that all fields imported are numeric except for the month field (use field manipulation). Add a computed (virtual) variable to compute the hourly rate paid for each employee. You can do this through the Field Manipulation "append" subcommand. Your new field should be "virtual numeric" with a length of 4 and 2 decimal places. You should name the field "payrate". Save the new file with this added variable as "aprilpayrol12".

3. Import the file "Employees".

4. Join the two files, "Employees" and "Aprilpayroll2", using the File/Join Databases command. When joining the files, match on the Employee Number (Aprilpayrool2) and ID (Employees) fields, as these two numbers should be the same for each employee. Use the AprilPayroll file as the primary file and add only the approved wage rate and employee name from the secondary file (Employees). Include all records from both files. Save the combined file as "payrollcombined".

5. Using the payrollcombined file, extract all records in which the pay rate does not equal the approved wage rate. Name the extraction file "payratecomparison". Save this file and print out the exception report.

\section{PART 2}

\section{Audit Objectives:}

To determine the extent of any differences between the physical inventory count and the perpetual inventory records.

To verify the accuracy of the physical count by determining if the count data includes any duplicate tag numbers, missing tag numbers, or extra tag numbers outside of the range of numbers used. The tags used were numbered 1-50.

To identify any products for which the quantities on hand per the perpetual inventory are less than the required minimum quantities set by management. 


\section{Audit Procedures:}

1. Import the inventorycount file.

2. Import the perpetualinventory file.

3. Join the two databases imported in steps one and two in order to have one file that contains both the inventory count per the physical inventory and the inventory quantities per the books. Match the files on drawer number and include all records. Name the new file "inventorycountcomparison". Any field that is included in both files, such as part number, should only be included once in the combined file.

4. Compare the quantity on hand per the books to the quantity counted by using the Extraction command. Name the output file "inventorycountmismatches".

5. In the file inventorycountmismatches, add a virtual variable that is the difference between the 2 quantities (books versus physical count). Print this file.

6. Import the inventory master file.

7. Using the inventorycountmismatches file as the primary file and the inventory master file as the secondary file, join the two files. Include only the price from the inventory master file in the new combined file. Match on the drawer number. Name the new file "inventoryadjustment".

8. Use the field manipulation command to create a variable which represents the dollar amount of the difference between the book quantity and the counted quantity for each part in the inventoryadjustment file. Call this variable "adjustment".

9. Create a formal report, using the File/Create Report command, that includes the Part Number, Drawer Number, Tag Number, Description, Quantity counted, Quantity on hand, Difference, Price, Adjustment, and a total for the adjustment field. Include a cover page with your name on it and a descriptive title. Print this report.

10. To test the accuracy of your physical inventory count records, use the inventory count file to look for duplicate, missing, or extra tag numbers. First, sort the data in the file by tag number. Then, test for missing tag numbers using the Gap Detection command. Print this report. This information would be used to compare to the tags to determine if any missing numbers were voided tags or if inventory was accidentally omitted from the file. Next, search for duplicate tag numbers and print out the resulting report. This information would be used to compare to the actual tags and determine if two products were included on one tag, or if there is an error. Next, search for any additional tags included in the count records but not authorized (outside of the sequence authorized, which was 1-50). Print out the results of this test.

11. Design a test to determine if any quantities on hand per the perpetual inventory are less than the required minimum quantities designated by management. Print a report that lists all products for which the stock is less than the minimum and the amount of the shortage for each product.

12. Prepare a brief executive summary of your testing results. 
$\underline{\text { NOTES }}$ 